OPEN ACCESS

Approved by:

Frontiers in Human Neuroscience

Editorial Office,

Frontiers Media SA, Switzerland

*Correspondence:

Liang Meng

promise_land@zju.edu.cn

Qingguo Ma

maqingguo3669@zju.edu.cn

Received: 12 February 2019 Accepted: 15 February 2019

Published: 06 March 2019

Citation:

Li D, Meng L and Ma Q (2019)

Corrigendum: Who Deserves My

Trust? Cue-Elicited Feedback Negativity Tracks Reputation Learning

in Repeated Social Interactions.

Front. Hum. Neurosci. 13:83

doi: 10.3389/fnhum.2019.00083

\section{Corrigendum: Who Deserves My Trust? Cue-Elicited Feedback Negativity Tracks Reputation Learning in Repeated Social Interactions}

\author{
Diandian $\mathrm{Li}^{1,2,3}$, Liang Meng ${ }^{4,5 *}$ and Qingguo $\mathrm{Ma}^{1,3,6 *}$ \\ ${ }^{1}$ School of Management, Zhejiang University, Hangzhou, China, ${ }^{2}$ Beijing Xinsight Technology Co. Ltd., Beijing, China, \\ ${ }^{3}$ Neuromanagement Lab, Zhejiang University, Hangzhou, China, ${ }^{4}$ School of Business and Management, Shanghai \\ International Studies University, Shanghai, China, ${ }^{5}$ Laboratory of Applied Brain and Cognitive Sciences, Shanghai \\ International Studies University, Shanghai, China, ${ }^{6}$ Institute of Neural Management Sciences, Zhejiang University of \\ Technology, Hangzhou, China
}

Keywords: trustworthiness, trust game, social learning, event-related potential, feedback negativity

\section{A Corrigendum on}

Who Deserves My Trust? Cue-Elicited Feedback Negativity Tracks Reputation Learning in Repeated Social Interactions

by Li, D., Meng, L., and Ma, Q. (2017). Front. Hum. Neurosci. 11:307. doi: $10.3389 /$ fnhum.2017.00307

There was an error in the Funding statement. The correct number for the National Project is "AWS14J011."

The authors apologize for this error and state that this does not change the scientific conclusions of the article in any way. The original article has been updated.

Copyright ( $\odot 2019$ Li, Meng and Ma. This is an open-access article distributed under the terms of the Creative Commons Attribution License (CC BY). The use, distribution or reproduction in other forums is permitted, provided the original author(s) and the copyright owner(s) are credited and that the original publication in this journal is cited, in accordance with accepted academic practice. No use, distribution or reproduction is permitted which does not comply with these terms. 